\title{
Challenges to a more open discussion of suicide
}

\section{The value and meaning of public discussion of suicide requires broader consideration}

ecently, some commentators have called for a more open public discussion of suicide to promote community awareness of this important issue. ${ }^{1}$ The rationale for this is based on international research that advocates a multilevel approach to suicide prevention, combining mental health care with public awareness campaigns and gatekeeper training for those in close contact with at-risk groups. ${ }^{2}$ While this is intuitively appealing, the problem is that, as well as being a public health problem, suicide is inscribed with deeply felt moral, religious and cultural meaning that will influence any discussion, and that the potential outcomes of public discussion are poorly understood.

Unfortunately, the debate about the public discussion of suicide has often failed to go beyond consideration of the risks of such a "dangerous" discourse and often conflates public discussion of suicide with media reporting of suicidal events. Indeed, there is very little research that investigates public discussion outside this context. ${ }^{3}$ Most existing research relates more specifically to the domain of news and information media, ${ }^{3}$ and the debate in Australia has often centred on media guidelines for the responsible reporting of suicide. ${ }^{1,4}$ Many of those who have contributed to debates about public discussion of suicide have noted that increased media reporting may have a detrimental effect and lead to increased suicidal behaviour in vulnerable, at-risk populations. ${ }^{4}$ In support of such concerns, they cite a strong body of research that demonstrates a correlation between media reporting of suicide and actual suicide. But while such research indicates the dangers of irresponsible or insensitive reporting of suicidal events, there is also a small body of literature that shows how media reporting of suicide may operate positively and reduce the risk of suicide.,

However, media representations of suicide and community discussions of suicide are two distinct issues. Many different kinds of conversations are possible (in terms of their focus, format, setting and target group). ${ }^{3}$ For example, it is possible to discuss prevention, intervention and postvention (for the bereaved); it is possible to have discussions online, in the workplace, within families and in educational settings; and it is possible to have one-on-one discussions, group discussions and community discussions. ${ }^{3}$ It is important, therefore, to recognise these differences and the potentially different impacts and implications that these might have. ${ }^{3}$

Most of the research on discussion of suicide focuses on individual-level interactions. For example, literature reviews conducted in New Zealand ${ }^{7}$ and Canada ${ }^{8}$ focus on the question of whether asking about an individual's suicidal ideation or intent increases the risk of that person
Scott J Fitzpatrick BA(Hons), PhD Candidate

Ian H Kerridge BA, MPhil, BMed, Associate Professor and Director

Centre for Values, Ethics and the Law in Medicine, University of Sydney, Sydney, NSW.

scott.fitzpatrick@ sydney.edu.au

doi: 10.5694/mjal2.11540

\section{A genuinely}

open discussion

of suicide must

be a wide

discussion -

not just a

medical or

public health

discussion either attempting or completing suicide — with neither study finding evidence to support or refute this claim. A review of the literature conducted on behalf of Choose Life, Scotland's national action plan to reduce suicide, adopted a broader approach, investigating individual-level discussions as well as general public education and awareness campaigns. ${ }^{9}$ Like the New Zealand and Canadian studies, the researchers found no evidence that encouraging people to talk about suicide had any positive or negative impacts on primary outcomes of decreasing suicidal acts or higher levels of treatment seeking. The same was true of public education and awareness campaigns, although there was some evidence to suggest that public awareness campaigns may increase awareness of suicide and available resources. ${ }^{9}$

The failure of research to demonstrate many measurable changes in complex social behaviour after health promotion campaigns is, in many ways, not surprising. There are intellectual and emotional barriers to discussing things that are painful, threatening and complex, ${ }^{10}$ and it is unrealistic to expect significant social change within a short period of time.

Limiting the outcomes of research to suicide rates and the number of people seeking treatment, as generally happens, is also problematic: these are not the only measures of success. Other meaningful outcomes of facilitated public discourse may include, for example, increased public tolerance of mental illness, reduction in discrimination and stigmatisation of both people who have attempted suicide and those with mental illness, increased awareness of the risk factors for suicide and increased community cohesion more generally. For suicide is not simply a medical "problem", or even a public health "problem" - it is a complex cultural and moral concern that is deeply embedded in social and historical narratives and is unlikely to be greatly altered by any form of health intervention.

While recent efforts by the New South Wales Ministry of Health to develop evidence-based guidelines for community discussion about suicide are welcome, ${ }^{3}$ we suggest that such approaches continue to confuse clinical with public discourse, persistently focus on the risk of public representation of suicide, and misapprehend the scope and benefit of public discussion.

The cultural conversation required to address deepseated issues of stigma, blame and social responsibility, as well as morally unsettling questions about the particular nature of the hopelessness and helplessness that compels individuals to contemplate suicide, is not easy to articulate and less easy to measure. And, like discussions of gender roles or racism with which we believe public discussion of suicide may be more suitably compared, any social or cultural transformation may take many years to achieve. Nor can such discussions ever be completely free of risk. Talking about grief, fear, loss, isolation and destruction will always be challenging and, irrespective of how sensitively 
it is done, some will inevitably find that such discussions do not reduce these feelings but amplify them. We can try, as best we can, to respond to these feelings, thoughts and anxieties when they arise, but we cannot imagine their possibility out of existence.

While medicalisation of suicide has provided secular ways to understand suicide and has enabled the development of therapies and programs to prevent its occurrence and to assist at-risk individuals and those bereaved by suicide, it has also led to a narrowing of public discussion. A genuinely open discussion of suicide must be a wide discussion - not just a medical or public health discussion, but a social, cultural, moral, political and even religious discussion.

Public conversations about suicide are happening and have always happened. Rather than seek to suppress or control such discussions, we need to understand that medicine does not have all the answers to such complex problems and to trust in people's capacity to reflect on even the most difficult issues. It is time for us to have a much richer, more honest and more open public discussion about suicide.

Competing interests: No relevant disclosures.

Provenance: Not commissioned; externally peer reviewed.

1 McGorry P. The sort of conversation we should be having about suicide. The Conversation [internet] 2011; 15 Apr. http://theconversation.edu.au/the-sort- of-conversation-we-should-be-having-about-suicide-663 (accessed Jan 2013).

2 van der Feltz-Cornelis CM, Sarchiapone M, Postuvan V, et al. Best practice elements of multilevel suicide prevention strategies: a review of systematic reviews. Crisis 2011; 32: 319-333.

3 NSW Ministry of Health. Community guidelines for discussing suicide project. Summary of the literature. Sydney: NSW Ministry of Health, 2012. http:// www.himh.org.au/_data/assets/pdf_file/0018/4833/CommunityGuidelines-Literature-Summary.pdf (accessed Jan 2013).

4 Kolves K. The facts about safe reporting of suicide. The Conversation [internet] 2012; 14 Sep. http://theconversation.edu.au/the-facts-about-safe-reportingof-suicide-9501 (accessed Jan 2013).

5 Jobes DA, Berman AL, O'Carroll PW, et al. The Kurt Cobain suicide crisis: perspectives from research, public health, and the news media. Suicide Life Threat Behav 1996; 26: 260-271.

6 Goldney RD. The media and suicide: a cautionary view. Crisis 2001; 22: 173-175.

7 Hall K. Suicide prevention topic 7: does asking about suicidal ideation increase the likelihood of suicide attempts? NZHTA report 2002. Otago: New Zealand Health Technology Assessment (NZHTA), 2002. http://www.otago.ac.nz/ christchurch/otago013987.pdf (accessed Jan 2013).

8 Centre for Suicide Prevention. Talking about suicide, asking the question. Calgary: Centre for Suicide Prevention, 2010. https://suicideinfo.ca/ LinkClick.aspx?fileticket=WSpsOkTerl4\%3d\&tabid=538 (accessed Jan 2013).

9 Gordon R, Angus K. Review of literature to identify whether encouraging people to talk about suicidal feelings is associated with any known/identified positive or negative outcomes and to identify any similar/relevant awareness raising/social marketing campaigns and their impact. Stirling, UK: prepared for Choose Life by the University of Stirling and The Open University, 2007. http://www.chooselife.net/uploads/documents/54-Literature\%20Review\% 20Final.pdf (accessed Jan 2013).

10 Owens C, Owens G, Belam J, et al. Recognising and responding to suicidal crisis within family and social networks: qualitative study. BMJ 2011; 343: d5801. 